\title{
Applications of energy security assessment in Strategic Environmental Assessment
}

\author{
Chi-Feng Chen ${ }^{1, *}$ \\ ${ }^{1}$ Department of Natural Resources, Chinese Culture University, Taipei, Taiwan R.O.C. \\ * Corresponding author. Tel: +886-2-28610511 ext 31432, E-mail: caf2@faculty.pccu.edu.tw
}

\begin{abstract}
Energy security is crucial for an energy policy but so far is not included in the current Strategic Environmental Assessment (SEA) program in Taiwan. The SEA report of energy policy prepared by the Bureau of Energy, Ministry of Economic Affairs, also demonstrated the same need. However, a feasible and quantifiable indicator has been missing. For the reason, this study is aimed to establish a practical assessment tool to assess energy security. Two indexes are suggested, which are the energy mix diversification (EMD) and energy import diversification (EID). The former one considers the national energy structures and expressed as Shannon index. The later is to assess the dependency on imported sources. The both indexes result in low energy security in Taiwan because of too high percentage of imported coal and oil in energy structure. The example of SEA policy is according to the Taiwan's Sustainable Energy Policy Framework, in which the energy efficiency is set to increase $2 \%$ annually in the future eight years. The increasing energy efficiency does not contribute significantly to improve energy security. The indexes used in this study can assess diversity of the whole energy structure and the imported energy sources, should benefit to SEA quality and energy security assessment.
\end{abstract}

Keywords: Strategic Environmental Assessment, Energy Security, Diversity.

\section{Introduction}

Strategic Environmental Assessment (SEA) is aimed to pre-assess the likely integrated environmental impacts from a policy, plan, or program (PPPs). Unlike a project with specific development content, the assessment scopes of SEA are vague and uncertain. In Taiwan, SEA is included in the Environmental Impact Assessment Act and the SEA Regulation is announced as the basic guideline. Energy policy is one of the listed policies which ought to carry out SEA under the Regulations. Several assessment items are appointed; however, these items cannot reflect the core issue of an energy policy, which is energy security. Energy security equals to national security and should be considered in SEA. Although energy security does not induce direct impacts on natural environment, it does impact significantly on the whole environment.

The SEA Regulation was announced in 2000 but only five cases completed to date. Sustainable Energy Development Framework was proposed by the Bureau of Energy. According to the requirement of SEA Regulations, the Bureau initiated the SEA in 2006 and the draft was completed in 2009. The SEA draft pointed out that the assessment items should be adjusted to specifics of policies to strengthen the relations between assessment items and policies. Thus, additional assessment factors, such as stability, efficiency, and clean of energy policy were suggested to be added.

Energy security is a complex issue and comprises diverse components, such as supply security, consumption security, production security, transportation security, ecological security, environmental security, and so on. Unfortunately, the definition of energy security is not received consensus (Loschel, et al., 2009). Due to the complicated definition, it is hardly to quantify its security level. Some definitions can be found in Bohi and Toman (1996), IEA (2007), Lin (2008), Commonwealth of Australia (2009), and Kruyt et al. (2009). In addition to the Taiwanese experiences, the assessment of energy security for SEA of energy policies is weak and obscure (Noble, 2002; Jay, 2010; Josimovic and Pucar, 2010). 
Therefore, the objective of this study is to establish feasible tools to address the impacts of PPPs on energy security. Energy security consists of three important respects, which are adequacy, reliability, and affordability (Commonwealth of Australia, 2009). Due to economic analysis is necessary to examine the affordability of energy policies and more monetary information are required, this study excludes the considerations of affordability and is focus on diversity or dispersion of energy policies as energy security assessment.

\section{Material and Method}

\subsection{Energy Security in Taiwan}

Taiwan depends on extremely high imported energy. The dependence on imported energy is up to $99.23 \%$ in 2008 , in which the dependence on oil is $49.5 \%$ and $83.62 \%$ of imported oil is from middle-east counties. The heavily high dependence on particular imported regions is a big challenge to conserve energy security. Besides, the imported value of oil occupies $19.35 \%$ of the whole imported value due to the increased oil price. It is the first time that the imported value of oil is larger than 10\% of GDP in Taiwan. Not only the high dependence on imported energy, but also the high energy consumption is opposite to the international trend which decreases fossil fuel usage. Chang (2004) compared oil supply of six Asia countries with Shannon-Weiner Index and concluded that high risk happened in Taiwan and Philippines. In these two countries, mostly oil is imported from west Africa where politics is unstable. Lin (2008) assessed Taiwanese energy security with economic model and demonstrated the decreased trend of energy security since 2000, because of the high energy intensive business structure. The official annual report addressed energy security with five indicators, including energy dependency on imports, energy dependency on oil, values of energy imports/total imports, oil imports dependency on the middle east, and oil dependency on imports. The major causes to low energy security in Taiwan are the high dependency on imported energy and imported oil.

\subsection{Strategic Environmental Assessment in Taiwan}

The implementation of SEA in Taiwan is based on the article 26 in Environmental Impact Assessment Act, in which the PPPs with significant environmental impacts should be assessed. The SEA Regulations was announced in 2000 and amended in 2005 and 2006. In the Regulations, ten policies are required to implement SEA. Until December, 2009, only five SEA cases were finished. Many arguments have been discussed, such the listed policies, assessment scope, and assessment tools. Basically, the policy proponent checks whether the proposed policy is listed in the Regulations. If yes, the proponent cooperates with professional agency to produce the SEA report and submit it to official administration. A consult committee under administration will do the final examination and feedback to the policy proponent. The SEA report is the supplement document provided to decision maker. Eight impact aspects are assigned in the Regulations, i.e., environmental capacity, natural ecology and landscape, public health and safety, land resources, water resources, cultural property, international environmental regulations, and society and economy. In each impact aspects, several sub-factors are listed. The final assessment results are expressed as qualitative symbols, $++,+, 0,-,--$. The symbols indicate significant positive effect, positive effect, none effect, negative effect, and significant negative effect, respectively.

\subsection{Energy Security Indicators}

The quantitative indicators for assessing energy security can be divided into two types. One is focus on particular aspect and uses individual indicator, such as the dependency on imported 
energy or imported oil, the percentage of imported energy, the concentration of energy supply, and so on. The other is integrated index, which combines several concerned aspects of energy security into one integrated index. for example, the energy security market concentration (ESMC) and energy security index (ESI) by International Energy Agency (IEA, 2007), and the Energy Indicators for Sustainable Development developed by International Atomic Energy Agency, which are to assess energy security with considerations of economic, social, and environmental impacts (IAEA, 2005; Vera and Langlois, 2007). Some indicators are incorporated with risk evaluations, such as geopolitical market concentration risk (Blyth and Lefévre, 2004) and risk weight in energy security (Wu et al, 2006).

The energy security should satisfy stable supply and affordable price (IEA, 2007). In this study, the stable supply is particularly considered in SEA and the economic impact on energy price is excluded at this stage. While considering the physical characteristic of energy security, the more vulnerable to physical disturbance means the less energy security. The vulnerability usually comes from less energy sources in energy structure or high dependency on particular sources. The diversification of energy policy is used to demonstrate the physical disturbance. Two commonly indices are developed for assessing diversity, i.e., ShannonWiener index and Herfindhal-Hirschman index. The shannon-wiener index is orginially served as a biodiversity measure, combinding the number of species and the proportion of each species. A value of shannon-wiener near to zero means that almost the sample is the same species, implying very low diversity. on the contrary, the great value indicates the species distribute more equally and the diversity is high. the herfindhal-hirschman index is a common meaure of market concentration. it is calculated by summng the squares of the maket share of each firm.

In Taiwan situation, the most important issue on energy security is to increase energy diversification because more than 99\% of energy in Taiwan is depended on imported energy. Therefore, indicators to assess energy diversity in energy policy is focused and two indicators are used in this study. Regarding to energy diversity, diversity in national energy structure, diversity in imported energy, and diversity in different energy sources are concerned. Two indicators are able to express the concerned diversity with simple calculation. They are Energy Mix Diversification (EMD) and Energy Imported Diversification (EID). The EMD mimics Shannon Index, considering the number and distributions of energy sources, to evaluate the national energy diversification. The EID further assesses the imported countries of the same energy source and the percentage of energy quantity from each imported country. The EID is able to reveal the imported distributions of particular energy source, such as oil, coal, or natural gas. Due to this indicator is focus on imported energy, high imported percentage of the overall national energy will decrease this indicator significantly. The two indicators share similar concept with Shannon index and ARE easily to use. The required information can be found in public annual statistic report and not necessary on complex computations. Although the core concept is similar, the highlights of the two indices are different. The EMD index focus on diversity of the whole energy structure and the EID underlines diversity of imported energy and diversity of each energy source as well.

The equations of the two indicators are as follows.

$$
E M D=-\sum_{i} p_{i} \times \ln p_{i}
$$




$$
E I D=\left(1-\sum_{i} p_{i}\right)\left(\frac{\sum_{i} p_{i} \times I_{i}}{\sum_{i} p_{i}}\right)
$$

where $p_{i}$ is the percentage of energy type $i$ in the overall energy (\%), $I_{i}$ is the imported diversity of energy type $\mathrm{i}$ and calculated by $I_{i}=-\sum\left(w_{i, j} \times \ln w_{i, j}\right)$. $w_{i, j}$ is the percentage of energy type i imported from country j.

\section{Results and Discussion}

\subsection{Energy security of the current policy}

The energy security indicators, EMD and EID, are used to demonstrate the past and current situation in Taiwan. The energy data is from official statistic report.

(1) EMD analysis

The energy sources in Taiwan are classified as seven types, i.e., coal, oil, natural gas, hydropower, nuclear energy, solar and wind power, and thermal energy. The highest diversity occurs when average distribution among the seven energy types, which is 1.95. However, more than $80 \%$ of energy is coal and oil. The EMD is ranged at $1.13 \sim 1.18$, depicted as Fig. 1(A). There is no significant change in the past 15 years, implying that the energy supply structure does not change, or, not improved.

(2) EID analysis

Except renewable energy, the fossil fuel and nuclear energy are almost imported. In 2008, the coal is imported from five countries and more than 90\% is from Australia and Canada. The oil is imported from seven countries and 55\% is concentrated in Saudi Arabia and Kuwait. The natural gas is also from seven countries and 65\% is from Indonesia and Malaysia. Therefore, the imported diversity of the different energy sources is $0.77,1.69$, and 1.52 for coal, oil, and natural gas, respectively. The performance of diversity of energy type shows that the diversity of oil is better because of the more imported countries and higher distributions. In addition, the percentage of the three energy types to the overall energy is $32.42 \%, 49.46 \%$, and $9.42 \%$ in 2008. Thus, the EID in 2008 is 0.117. The EID trend is as Fig. 1(B). Due to the dependency on imported energy is too high, the EID value is very low.

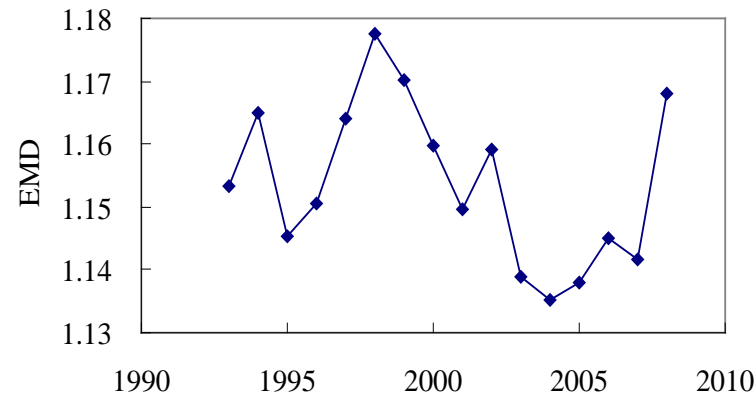

(A)

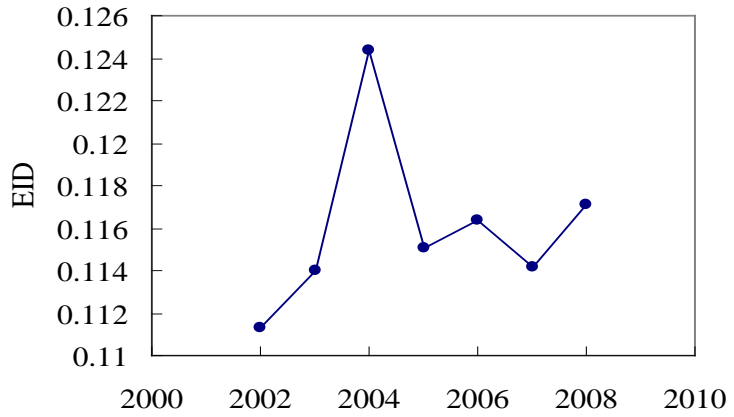

(B)

Figure 1 The results of (A) EMD index and (B) EID index in Taiwan. 


\subsection{Energy security of Sustainable Energy Development Framework}

(1) scenario of energy policy

The lately announced energy policy in Taiwan is the Sustainable Energy Development Framework. In this study, one of the strategies listed in the framework is used to demonstrate the energy security assessment. Many objectives are set in this Framework and one of them is to increase energy efficiency. In this study the objective of energy efficiency is used as energy policy scenario, in which the energy efficiency is increased $2 \%$ annually in future eight years and the energy intensity (or energy consumption) is decreased $20 \%$ of the level of 2005 by 2015.

The energy efficiency is the ratio of energy production to input, expressed as NT\$/ LOE (New Taiwanese Dollar/ litter of equivalent oil). In 2009, the energy efficiency is $113 \mathrm{NT} \$ / \mathrm{LOE}$ and the value will become 133 NT\$/LOE in 2017 under the policy scenario. If the production is $1000 \mathrm{NT}$, the 8.85 litter of oil is required in 2009; however, only 7.52 litter of oil is required in 2017 according to its higher energy efficiency. Therefore, the $15 \%$ of energy will be saved in 2017 if assuming other impact factors are maintained. This means primary energy consumption of 121,333 thousand kLOE in 2009 will decrease to 103,557 kLOE in 2017. The total saved oil is 17,776 thousand kLOE in 2017. The assumed trend of energy efficiency and primary energy is showed in Fig. 2. After translating the policy objective into the detailed energy change information, the information is used to assess the impact of energy security incurred by the policy.

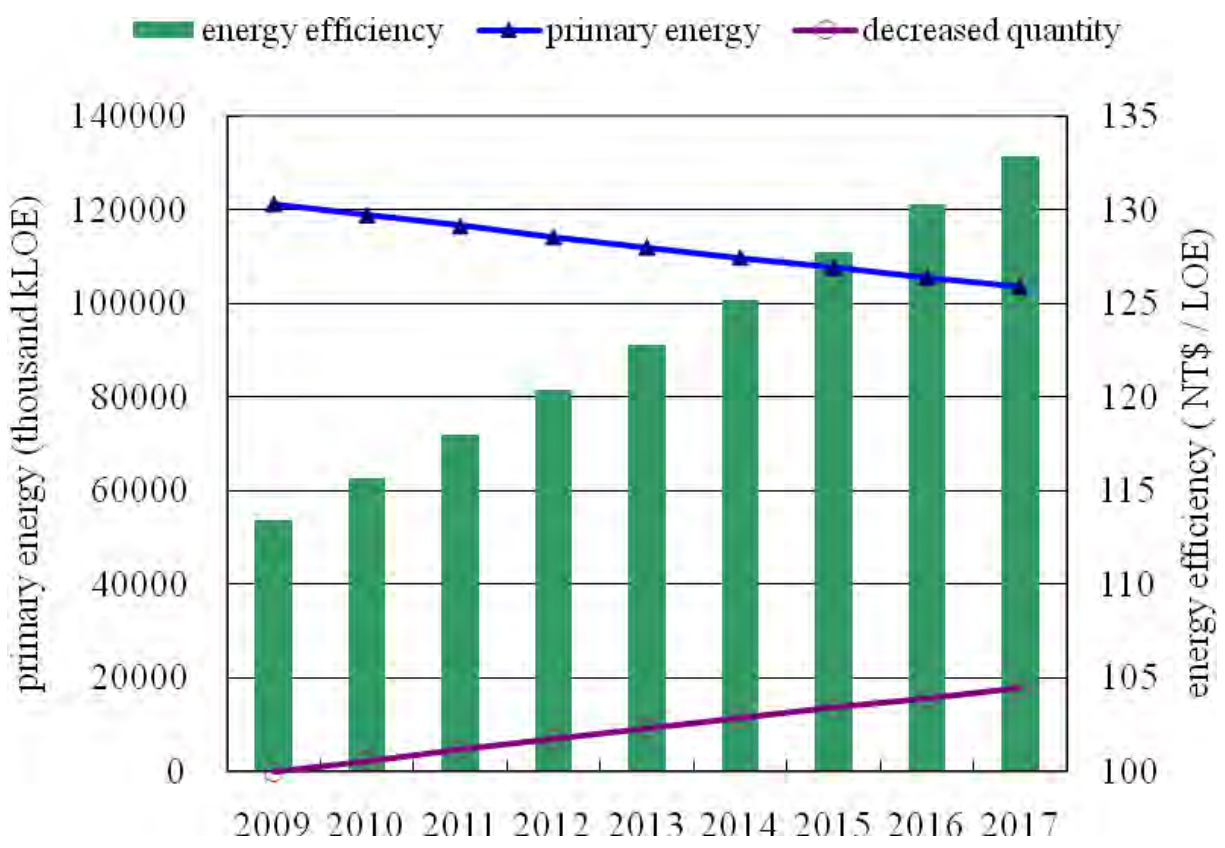

Figure 2 The simulated trend of energy efficiency and primary energy under the scenario of increased $2 \%$ of energy efficiency annually in eight years (base year 2009).

(2) EMD analysis

Due to the increased energy efficiency, the total of 17,776 thousand kLOE can be saved in 2017. If the saved energy is contributed to coal and oil savings and the other energy maintains as the same quantity in 2009. The energy structure is then changed as Fig. 3. The percentage 
of coal is from $34.6 \%$ in 2009 decreased to $31.9 \%$ in 2017 and the oil is from $45.2 \%$ to $44.4 \%$.

The performance of EMD is 1.167 in 2009 and 1.254 in 2017 because of the decreasing percentage of coal and oil. Although the distribution of energy sources is slightly raised because of the improved energy efficiency, the EMD value is still less than Japan and Korea, which is 1.38. The big difference is caused by the high percentage of coal and oil. Even in 2017 scenario, the percentage of coal and oil is summed up to 76.3\%. However, this value in Japan and Korea is less than $70 \%$, which implies that the improvement of energy efficiency seems not contribute significantly to energy security and the developments of the other energy are important as well.
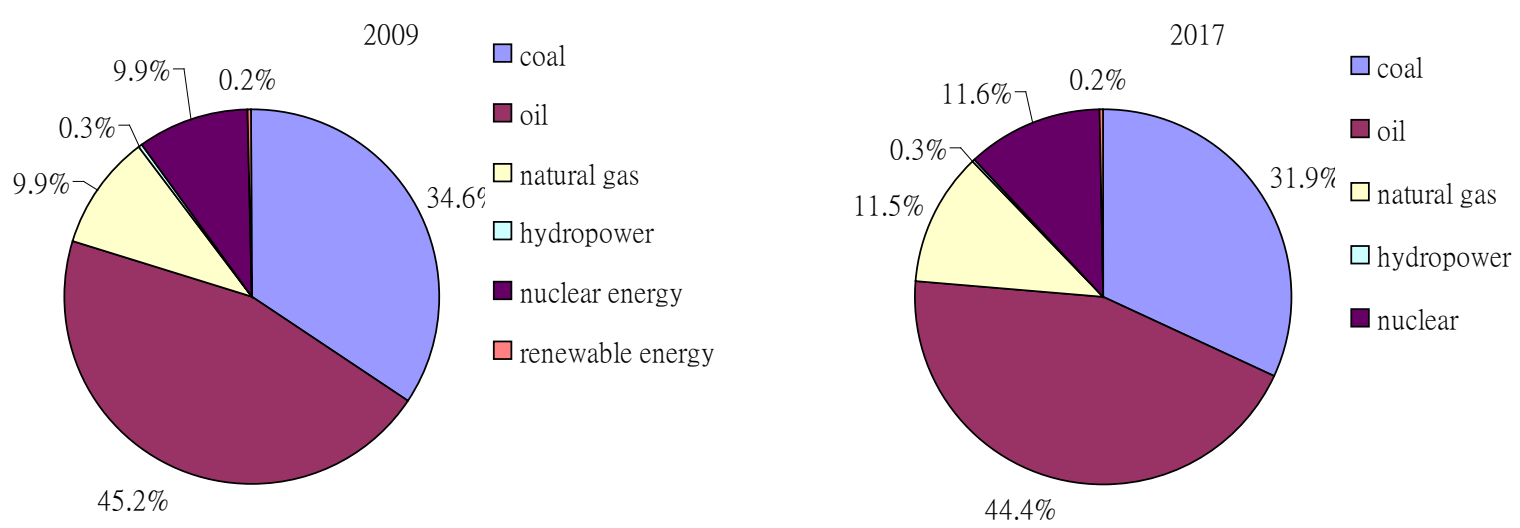

Figure 3 The energy structure in 2009 and 2017

(3) EID analysis

There is no detailed information about the change of energy imported countries under the scenario of improved energy efficiency. Assuming the number and distribution of energy imported countries is the same with that in 2009, i.e., 0.77 for coal, 1.69 for oil, and 1.52 for natural gas. But the percentage of coal, oil, and natural gas to the overall energy is changed, the final EID is therefore from 0.117 in 2009 to 0.164 in 2017. The more diversity energy structure in 2017 results a better consequent EID value as well.

\section{Conclusions}

Energy security is the core issue of energy policy and should be included in SEA. However, assessing energy security is difficult due to its indistinct definition and no indicators can reflect the complete energy security. The need of a quantitative tool of energy security is obvious in Taiwan; especially applying it in SEA. This study clarifies the physical characteristics of energy security and suggests that diversification can represent the energy security. Two indicators are proper to quantify the diversification, which are energy mix diversification (EMD) and energy imported diversification (EID). The EMD reveals the diversification of the national energy structure. When disperse the dependency on particular energy sources, the EMD will sequentially increase. The EID is an advanced indicator and is able to reflect the imported diversity of a particular energy type.

In Taiwan, the domestic energy production is very low and almost 99\% of energy depends on imported energy. The results of EMD and EID show the consistent low energy security. The current energy structure is heavily relied on coal and oil and results in low EMD value. The high percentage of imported energy causes low EID value. Even increasing energy efficiency 
according to the objective of a newly energy policy, the improvement on energy structure is limited. Unless the dependency on coal and oil is decreased to less than $70 \%$, the energy security would not promote dramatically in Taiwan.

\section{Reference}

[1] Loschel, A., Moslener, U., Rubbelke, D., 2009, Indicators of energy security in industrialized countires. Energy Policy doi:10.1016/j.enpol.2009.03.061.

[2] Bohi, D. R. and M. A. Toman, 1996, The Economics of Energy Security, Norwell, Massachusetts : Kluwer Academic Publishers.

[3] International Energy Agency (IEA), 2007, Energy Security and Climate PolicyAssessing Interactions, p. 150.

[4] Lin, S.M., and Fon, C.C., 2008, Energy security assessment in Taiwan, 2008 Annual conference of Taiwan Economy Association, Taiwan.

[5] Commonwealth of Australia, 2009, National Energy Security Assessment.

[6] Kruyt, B., van Vuuren, D.P., de Vries, H.J.M, Groenenberg, H., 2009, Indicators for energy security. Energy Policy 37: 2166-2181.

[7] [7] Noble, B.F., 2002, Strategic environmental assessment of Canadian energy policy, Impact Assessment and Project Appraisal, 20 (3), pp. 177-188, Beech Tree Publish, UK.

[8] [8] Jay, S. 2010, Strategic environmental assessment for energy production, Energy Policy, 38, pp. 3489-3497.

[9] Josimovic, B., and Pucar, M., 2010, The strategic environmental impact assessment of electric wind energy plants: Case study ‘Bavaniste’ (Serbia), 35, pp. 1509-1519.

[10]Chang, S.L., 2005, Feasibility analysis of energy supply security and oil dispersion policy, International Conference on Sustainable Energy Development and GHGs Mitigation, Taipei, Taiwan.

[11] International Atomic Energy Agency (IAEA), 2005, Energy indicators for sustainable development: guidelines and methodologies, p.171.

[12] Vera, I., Langlois, L., 2007, Energy indicators for sustainable development. Energy 32: 875-882.

[13] Blyth, W. and N. Lefévre, 2004, Energy Security and Climate Change Policy Interactions: An assessment framework, Paris: IEA.

[14]Wu, G., Liu, C.C., Fang, I., Wei, I.M., 2006, Analysis of risk on imported oil with HHA method, Cross Conference on Energy Economy and Policy, Beijing, China. 